\title{
La insoportable levedad de la justicia correctiva en el Derecho Contractual
}

\author{
Diego Papayannis*
}

Resumen: Papayannis enfoca sus objeciones en dos puntos primordiales de la Escuela de Toronto - a la que pertenece Martín Hevia y sostiene en su libro Reasonableness and Responsibility-. E1 primero es el énfasis en la bilateralidad de las relaciones de derecho privado; y el segundo es que las normas referidas a la celebración y el cumplimiento de los contratos o a la compensación de los daños que nos causamos unos a otros expresan un modo de ordenación adecuada para los asuntos privados. En conclusión, Papayannis sostiene que Hevia no logra mostrar que su teoría se distinga de modo relevante de las concepciones libertarias en lo que hace al derecho contractual.

Palabras clave: contratos, bilateralidad, obligaciones.

Abstract: Papayannis focuses his objections in two basic points of the School of Toronto - to which Martin Hevia belongs and supports in his book Reasonableness and Responsibility - The first one is the emphasis in the bilaterality of the relations of private right; and the second one is that the procedure referred to the celebration and the fulfillment of the contracts or to the compensation of the hurts that we cause to others express a way of arrangement adapted for the private matters. In conclusion, Papayannis holds that Hevia does not achieve to show that his theory differs in a relevant way from the libertarian conceptions in what it does to the contractual right.

Key words: contracts, bilateralism, obligations.

* Profesor Agregado de Filosofía del Derecho, Universidad de Girona. Este trabajo fue realizado en el marco del proyecto DER2014-52130-P, del Ministerio de Economía y Competitividad (España).

Email: diegomartin.papayannis@udg.edu 


\section{Introducción}

Reasonableness and Responsibility es un libro excelente. Es una profunda reflexión filosófico-política sobre el derecho de los contratos. Debo decir que simpatizo con muchas de las ideas allí expresadas por Martín Hevia. De hecho, una parte importante de las críticas que ofreceré a continuación no están lejos de tener impacto sobre mi propia visión del derecho privado. Por ello, este ensayo constituye un ejercicio interesante para mí, en tanto me exige tomar distancia de mi trabajo y volver de manera desprejuiciada sobre algunas tesis hasta ahora ubicadas en el centro del esquema con el cual he pensado la responsabilidad en el ámbito del derecho civil.

Enfocaré mis objeciones en dos puntos que para la escuela de Toronto - a la que Hevia pertenece intelectualmente- son casi sagrados. El primero es el énfasis en la bilateralidad de las relaciones de derecho privado. Se dice usualmente que las partes de un contrato están normativamente vinculadas de un modo muy especial. Las obligaciones que surgen de los contratos son obligaciones que uno debe a su contraparte exclusivamente. Nadie más que la contraparte tiene derecho a exigir el cumplimiento y a nadie más que a la contraparte se debe la prestación. En este sentido, los contratos tienen efecto relativo $\mathrm{y}$, por consiguiente, nadie que no sea parte puede demandar con base en las obligaciones que surgen de ellos ${ }^{1}$.

La segunda cuestión, íntimamente vinculada con la anterior, es que las normas referidas a la celebración y al cumplimiento de los contratos o a la compensación de los daños que nos causamos unos a otros expresan un modo de ordenación adecuada para los asuntos privados. Típicamente, se trata de instituciones de justicia correctiva. Las consideraciones de justicia distributiva quedan al margen de estas relaciones, pues la inferencia que lleva a un juicio de responsabilidad (contractual o extracontactual) solo toma en cuenta a las partes de la interacción, concebidas como agentes morales libres e iguales,

1 Hevia, M., Reasonableness and Responsibility: A Theory of Contract Law. Dordrecht, Springer, 2013. 
capaces de autodeterminarse ${ }^{2}$. Aunque Hevia intenta mostrar cómo estas interacciones privadas tienen lugar en un trasfondo de justicia distributiva, las interacciones en sí mismas no deben ser comprendidas como parte de ella. En otras palabras, ni los contratos ni los remedios contractuales pueden ser vistos como una manera de lograr una distribución justa de los recursos entre los miembros de la comunidad. Son, en cambio, una manera de lograr justicia entre particulares.

Combinando estas ideas, tenemos que las razones que el derecho contractual parece expresar son relativas a los agentes, en contraste con las razones neutrales a los agentes, como las que surgen en contextos distributivos. Si Axileas celebra un contrato con Xenofonte, solo Axileas tiene razones para cumplir ese contrato. Sería inapropiado exigir a Telémaco, si este no se obligó como fiador, la prestación debida por Axileas. Pero ello no es así para las razones de la justicia distributiva. Estas razones no son específicas para un agente. Este contraste es útil para comprender el modo de ordenación del derecho privado y su diferencia con algunas relaciones establecidas en el derecho público. La estructura bilateral del derecho privado, el hecho de que brinde razones específicas o relativas para los agentes es un rasgo del cual toda teoría debe dar cuenta.

Esta imagen está bastante arraigada en la teoría del derecho civil, pero con el tiempo he llegado a pensar que podría ser una exageración dogmática más que una necesidad conceptual o un presupuesto normativo de una interpretación liberal de estas instituciones, tal como asumen la mayoría de los autores. Por ello, intentaré argumentar que hay varias formas de entender el derecho contractual entre las cuales la justicia distributiva supone mucho más que un trasfondo en el que se desenvuelven las partes. Asimismo, las doctrinas que conforman el llamado carácter bilateral de los contratos, al menos en el derecho continental, admiten más de una excepción importante, por lo que difícilmente pueda tratarse de una cuestión esencial para comprender la "racionalidad inmanente" de las relaciones del derecho privado.

2 Weinrib, E., The Idea of Private Law, Cambridge-Mass, Harvard University Press, 1995. 
En definitiva, sostendré que el énfasis exagerado en la bilateralidad supone una distorsión descriptiva del derecho contractual, por una parte, y, por otra, un escoyo al momento de apreciar las múltiples formas en que el derecho privado puede abordar cuestiones públicas, más propias de la justicia distributiva.

Presentaré mi argumento en el siguiente orden: en la sección 2 ofreceré un panorama de las ideas que considero centrales en teoría de Hevia. En la sección 3, sostendré que Hevia es incapaz de ofrecer una verdadera alternativa a la concepción libertaria del derecho contractual. En la sección 4, esgrimo una defensa contra las críticas de Hevia a las teorías que, como la de Anthony Kronman, entienden las reglas del derecho de los contratos como una cuestión de justicia distributiva. En las secciones 5 y 6 elaboro argumentos adicionales para aceptar que la mayor parte de la regulación contractual es una cuestión de justicia distributiva y no de justicia correctiva. En la sección 7 , discuto el mito de la bilateralidad y el efecto relativo de los contratos. Finalmente, en la sección 8 , señalo dónde radica el carácter privado del derecho privado.

Para el lector que no nos conoce vaya esta advertencia: tengo la mayor estima personal y académica por Martín Hevia. Lo considero un amigo y, justamente por ello, no dejaría de criticarlo como merece. Dicho esto, cualquier cortesía adicional estaría fuera de lugar.

\section{II.El argumento principal de Razonabilidad y responsabilidad}

Hevia comienza desestimando dos maneras igualmente incorrectas, en su opinión, de concebir la justicia. Ambas posturas son monistas, en el sentido de que consideran que los principios que rigen el diseño de las instituciones sociales son los mismos que regulan la conducta individual de las personas ${ }^{3}$. Así, algunos teóricos entienden el fundamento

3 Murphy, L. B., Institutions and the Demands of Justice, Philosophy and Public Affairs, 1999; Hevia, M., Razonabilidad y responsabilidad: Rawls, Kant y la teoría del derecho contractual, 2014. 
último de todas las instituciones, incluido el derecho contractual, en términos de justicia distributiva, mientras que para otros se halla en la justicia correctiva.

El problema de estas posturas extremas es que no logran captar cómo las sociedades liberales se organizan mediante una división de la responsabilidad entre la comunidad y los individuos. Para Hevia, veremos más adelante, la comunidad en su conjunto se encarga de establecer un contexto distributivo razonable en el cual las personas pueden interactuar y perseguir su plan de vida. El derecho de los contratos es el mecanismo que los individuos tienen a su disposición para utilizar los bienes a los que tienen derecho, enajenándolos gratuitamente o a cambio de otros bienes, según lo requiera su proyecto de vida. Una vez que la comunidad cumple con su parte y establece un contexto distributivo justo, la distribución que resulte de los acuerdos privados será también justa, en tanto los individuos tienen que asumir la responsabilidad por las decisiones que toman, y ello exige soportar las consecuencias de esas decisiones. Al ignorar el principio de división de responsabilidad, los distributivistas se ven forzados a interpretar las transacciones privadas también a la luz de la justicia distributiva. Pero si las razones de justicia distributiva no son específicas para los agentes, estas posturas serán incapaces de explicar el efecto relativo de los contratos o el hecho de que las obligaciones contractuales sean obligaciones debidas por y a personas determinadas.

En el extremo opuesto, los libertarios como Robert Nozick han entendido que las teorías de la justicia distributiva son incompatibles con la idea de libertad individual. La libre interacción humana generará necesariamente desigualdades distributivas. Las partes en cada uno de sus acuerdos negociarán una distribución del excedente cooperativo y ello hace imposible para el Estado garantizar un patrón de distribución específico. Para lograrlo, deberían impedirse ciertos acuerdos básicos, como las donaciones y muchos tipos de contratos, o poner en funcionamiento instituciones eminentemente redistributivas, como el derecho tributario y el gasto público. Con cualquiera de estas herramientas, la distribución preferida socialmente podría lograrse solo a costa de coartar la libertad de las personas. La única 
regulación admisible es la de los acuerdos privados. Todas las instituciones sociales están justificadas en la medida en que respeten los principios fundamentales de la interacción individual. Contra los libertarios, Hevia intenta mostrar que la justicia distributiva es compatible con la libertad de las personas cuando se advierte cómo funciona la división de la responsabilidad. En un momento veremos exactamente la manera en que este principio se plasma en las sociedades liberales contemporáneas.

Las posiciones monistas, entonces, son distorsivas por dos razones opuestas. Los distributivistas se ven forzados a interpretar el mundo de la interacción privada como una instancia de la ordenación pública, mientras que los libertarios interpretan el mundo dela ordenación pública como un producto agregado de la interacción privada. La división de la responsabilidad, en cambio, preserva la intuición de que en las sociedades liberales algunas cuestiones son públicas y otras privadas.

En líneas generales, Hevia adhiere al desarrollo de Arthur Ripstein. Explica este autor que la clave para comprender la relación entre la justicia distributiva y la justicia correctiva está en la idea de división de la responsabilidad a la que Rawls hizo referencia, casi al pasar, en Social Unity and Primary Goods ${ }^{4}$. La división de la responsabilidad implica que la sociedad, como agente colectivo, asuma el compromiso de sostener un sistema de libertades básicas y de igualdad de oportunidades, a la vez que los individuos acepten la responsabilidad de revisar y adecuar sus planes de vida teniendo en cuenta los bienes primarios que tendrán a su disposición. Los bienes primarios son bienes que todas las personas racionales desean, tales como los derechos, las libertades y las oportunidades, el ingreso y la riqueza, entre otros; por su naturaleza, los bienes primarios son funcionales a cualquier plan de vida que uno escoja ${ }^{5}$. La división de la responsabilidad supone que los individuos toman responsabilidad por el plan de vida que llevan

${ }^{4}$ Rawls, J., "Social Unity and Primary Goods", en Sen, A. y Williams, B. (eds.): Utilitarianism and Beyond. Cambridge, Cambridge University Press, 1982; Ripstein, A., The Division of Responsibility, Fordham Law Review, 2004.

5 Rawls, J., A Theory of Justice, (Revised Edition) Cambridge, Mass., Harvard University Press, 1999. 
adelante $y$, en ese sentido, moderan sus exigencias a las instituciones sociales. En síntesis, los individuos solo pueden exigir a las instituciones sociales aquello que es razonable esperar de ellas. La comunidad no se responsabiliza por los errores de juicio de los individuos que conciben y emprenden proyectos desproporcionados en relación con los bienes primarios que constituyen su porción distributiva justa. Semejante exigencia escapa a la idea de razonabilidad.

De aquí se sigue que las obligaciones de la sociedad se limitan a que cada uno tenga una porción equitativa de bienes primarios. Una vez satisfecha esta obligación, corresponde a los individuos particulares aceptar su responsabilidad por cómo resultan las cosas. Cada uno llevará adelante su vida de acuerdo con su propia concepción de lo bueno. Dado que el individuo internaliza los beneficios de un plan exitoso, no puede trasladar los costes del fracaso al resto de la sociedad. Es decir, no puede exigir de las instituciones más bienes de los que constituyen su porción equitativa cuando esta resulta insuficiente para el plan que ha elegido. Ahora bien, señala Ripstein, para que tenga algún contenido la idea de que cada persona es responsable por cómo resulta su vida, debe comprendérsela en términos de la responsabilidad entre los ciudadanos privados. Carece de sentido afirmar que cada uno es responsable por lo que hace con su vida, si tuviese que soportar los daños que otros le causan o pudiese externalizar los costes de sus cursos de acción infligiendo daños a otros ${ }^{6}$.

En este marco, el derecho contractual es un conjunto de estándares públicos de comportamiento. Los individuos deben ser capaces de perseguir sus planes de vida de manera compatible. Por ello, reconocen límites recíprocos a su libertad. La interacción privada ha de ser voluntaria, ya que lo contrario violaría el imperativo categórico kantiano según el cual las personas deben ser tratadas como fines en sí mismos y no como medios. Existe una asociación conceptual entre las personas y sus fines, por una parte, y las cosas y los medios, por la otra. En cualquier caso, las personas deben tratarse recíprocamente como personas y no como cosas. De ahí que nadie deba imponer

${ }^{6}$ Ripstein, A., The Division of Responsibility, Fordham Law Review, 2004. 


\section{Diego Papayannis}

unilateralmente los términos de la interacción a su contraparte. No hay mucho más que pueda decirse sobre el derecho de los contratos a partir de la idea de división de la responsabilidad. Por ello, Hevia completa su teoría con elementos de una interpretación rawlsiana de la teoría del derecho privado de Kant. No es necesario por ahora ahondar en mayores detalles al respecto. Con lo que he dicho hasta aquí es suficiente para evaluar si está realmente justificado el rechazo de las dos visiones monistas que Hevia critica inicialmente.

\section{Las teorías libertarias y el trasfondo de la justicia}

Tengo la impresión de que Razonabilidad y responsabilidad no ofrece realmente un argumento contra la interpretación libertaria del derecho contractual. Dicho rápidamente, la razón de ello es que tanto la teoría libertaria de los contratos como la que se deriva del principio de división de la responsabilidad conciben al derecho contractual como un mecanismo para disponer de aquellos bienes (o derechos) que los individuos tienen la potestad de transferir a otros. Permítaseme explicar.

Nozick objetó que las teorías de la justicia distributiva requieren interferir constantemente con la libertad de las personas a fin de mantener el patrón distributivo deseado. Veamos un ejemplo sencillo. Tomemos una teoría de la justicia distributiva como la de Aristóteles ${ }^{7}$. Toda distribución implica un objeto a repartir entre dos o más personas con algún criterio. Las distintas teorías sustantivas difieren en cuanto al criterio relevante. Algunas entienden que la necesidad es el criterio distributivo adecuado, otras la capacidad, etc. Para nuestros propósitos no es necesario especificar qué criterio determina el mérito de las partes, sino solo asumir que existe un criterio que lo determina. Así, una distribución es justa si el objeto está repartido entre los individuos respetando su mérito relativo de acuerdo con el criterio relevante. Si el objeto a distribuir son 100 dracmas y las partes de la distribución son Axileas y Xenofonte, una distribución será justa entre ellos si las porciones que tocan a cada uno guardan una correlación 
proporcional con sus respectivos méritos. Si Axileas tiene 1/3 del mérito de Xenofonte (tiene un tercio de la capacidad o un tercio de la necesidad, etc.), entonces, la distribución justa es que Axileas tenga 25 y Xenofonte 75, pues la porción que cada uno recibe mantiene la misma proporción que su mérito: $25 / 75=1 / 3$.

Evidentemente una teoría de la justicia de este tipo está sujeta a las objeciones de Nozick, puesto que las nociones de libertad y responsabilidad tienen escaso lugar en ella. Imaginemos que el mérito está dado por la capacidad. En ese contexto, si Xenofonte es 3 veces más capaz que Axileas es justo que tenga el triple de los recursos. Pero si Xenofonte desease donar 10 dracmas a Axileas el patrón distributivo se vería alterado. Ahora ese contrato de donación debe ser objetado por la justicia distributiva, ya que de ser válido las porciones asignadas dejarían de guardar relación con el mérito de cada individuo: $1 / 3 \neq$ 35/65. Asimismo, si Axileas destruye 10 dracmas de Xenofonte y algún principio rectificatorio le ordena compensar, la responsabilidad de Axileas es incompatible con el patrón deseado, ya que $1 / 3 \neq 15 / 75$.

Como alternativa, Nozick propuso una teoría que consta de tres principios fundamentales: un principio de adquisición legítima, un principio de transferencia y un principio de rectificación de las injusticias. Las posesiones de los individuos serán justas si todos tienen derecho a ellas según los dos primeros principios. Por tanto, un individuo tiene derecho al recurso si lo adquiere legítimamente, ya sea de manera originaria o por transferencia voluntaria de alguien que a su vez lo adquirió legítimamente ${ }^{8}$. No me interesa analizar el problema de la adquisición originaria legítima, ni las posibles limitaciones de Nozick en este punto, sino solo mostrar que una teoría como esta no tiene las dificultades de las teorías de la justicia distributiva para hacer lugar a la libertad y responsabilidad individuales. Sin embargo, la razón por la cual no tiene dificultades es que para Nozick la justicia distributiva, cuando se la concibe del modo en que lo hizo Aristóteles, es un concepto engañoso que nos lleva a pensar que existe una distribución central de recursos comunes... pero según su visión no existe tal

8 Nozick, R., Anarchy, State, and Utopia. Oxford, Blackwell Publishers, 1974. 
cosa: "lo que cada uno tiene, lo obtiene de otro a cambio de algo, o como obsequio" ". No existe nada común que distribuir. De hecho, el argumento principal de Anarchy, State and Utopia intenta mostrar de qué manera podría nacer el Estado sin violar los derechos de ningún individuo, lo que exige siempre que el acuerdo sea voluntario. En este esquema no son los individuos los que tienen derecho a una parte del acervo común, sino que el acervo común lo conforman los individuos con sus contribuciones (en última instancia voluntarias) a fin de que ciertos servicios, básicamente de seguridad, puedan ser brindados. Por ello, el mundo de Nozick es un mundo dominado casi por completo por la justicia de las transacciones privadas. La justicia de las posesiones que cada uno tiene depende simplemente de que se haya observado el procedimiento justo para la adquisición y transferencia de los recursos (o derechos).

Hevia ofrece un argumento para mostrar que Nozick asume injustificadamente que tiene el monopolio de la idea de "justicia procedimental pura" 10 . La teoría de Rawls requiere que la estructura básica de la sociedad, aquellas instituciones que distribuyen los bienes primarios, sea justa. Con un trasfondo de justicia distributiva, las personas son responsables por el plan de vida elegido y deben asumir las consecuencias de sus decisiones. De esta forma, si en un contexto distributivo justo Xenofonte se empobrece lícitamente en un contrato con Axileas, el resultado distributivo final también será justo. Lo mismo si Axileas es obligado a compensar los daños que causa a Xenofonte. Al existir una división de la responsabilidad entre la sociedad y los particulares, Axileas no puede demandar a la comunidad más recursos una vez que sus malas decisiones lo llevaron a sufrir pérdidas considerables.

Lo importante a nuestros efectos es observar que los contratos en la teoría libertaria definen las condiciones en las que los individuos pueden transferirse mutuamente recursos o derechos. Como afirma Barnett,

9 Ídem.

${ }^{10}$ Rawls, J., A Theory of Justice, (Revised Edition) Cambridge, Mass., Harvard University Press, 1999. 
La insoportable levedad de la justicia correctiva en el Derecho Contractual

el derecho contractual es aquella parte del sistema de derechos que identifica las circunstancias en las que los derechos pueden ser válidamente transferidos de una persona a otra mediante su consentimiento, y es este último componente de carácter moral el que distingue las transferencias válidas de derechos enajenables de las inválidas ${ }^{11}$.

En otras palabras, el derecho contractual depende de un sistema general de derechos - solo puede funcionar en ese esquema- y el contenido del sistema general de derechos está justificado por una teoría de la justicia. La única diferencia entre la concepción libertaria y la que ofrece Hevia es que para los primeros el derecho natural sobre el propio cuerpo y el fruto de su trabajo determina que la distribución sea un paso previo a la cooperación — no hay cooperación si no se acuerda primero en una distribución de los excedentes-, mientras que para los rawlsianos la cooperación social tiene prioridad conceptual y, por ello, debe implementarse un esquema razonable para repartir los beneficios de esa cooperación.

Sea como fuere, los libertarios pueden dar cuenta del derecho de los contratos en los mismos términos que Hevia, puesto que sus diferencias se remontan a la teoría subyacente de los derechos que cada corriente asume. Para los libertarios, el contexto en el cual tienen sentido las interacciones privadas es aquel en el cual nadie es coaccionado, todos disfrutan de su autopropiedad y pueden determinar su vida autónomamente. Para los rawlsianos como Hevia, el trasfondo que garantiza la razonabilidad de las interacciones privadas es uno en el cual la comunidad asume la responsabilidad social de establecer una estructura básica justa. Dicho de otro modo, los libertarios entienden que los individuos tienen derecho a los bienes que adquieren legítimamente por apropiación justa o transferencia voluntaria, mientras que en la teoría de Hevia los individuos tienen los recursos que la estructura básica les garantiza. Para ambos enfoques, el derecho contractual

${ }^{11}$ Barnett, R., A Consent Theory of Contract, Columbia Law Review, 1986, citado por la traducción de Haymes, G. I. y Papayannis, D. M., La teoría consensual del contrato, Lecciones y Ensayos, 2006. 
tiene por función regular la transferencia legítima de esos bienes. Sea cual fuere el caso, las decisiones que tomen los individuos sobre qué bienes transferir y a quién transferirlos son su exclusiva responsabilidad. Por lo tanto, Hevia comparte con los libertarios mucho más de lo que sugiere en Razonabilidad y responsabilidad ${ }^{12}$ y, si tengo razón, ello hace que su rechazo general de las teorías monistas para comprender el derecho contractual no esté del todo justificado.

\section{Primer argumento distributivo: la sugerente teoría de Kronman}

En lo que hace a los distributivistas, Hevia toma la teoría de Kronman como representante paradigmático y elabora una serie de objeciones contra ella. Como es bien sabido, Kronman sostuvo que el rol del consentimiento en el derecho contractual no puede tener ningún valor justificatorio si se lo entiende con independencia de consideraciones distributivas ${ }^{13}$. Ello es así por una sencilla razón. Existe un sentido trivial en el cual incluso quien acepta obligarse a punta de pistola consiente la obligación. El director de orquesta al que Luca Brasi apuntó en la cabeza "consintió" liberar a Johnny Fontane de su contrato a cambio

${ }^{12}$ Hevia es claro respecto de su propósito: intenta mostrar simplemente que los libertarios se equivocan al asumir que la libertad de contratación y las consideraciones distributivas son incompatibles (Hevia, M., Reasonableness and Responsibility: A Theory of Contract Law. Dordrecht, Springer, 2013). Mi argumento es que la teoría del derecho contractual que Hevia articula no sería rechazada por ningún libertario, pues ellos asignan a esta rama del derecho las mismas funciones que Hevia. Para decirlo de otro modo, los libertarios entenderían que la teoría del derecho contractual de Hevia es correcta, pero incompatible con su marco rawlsiano. Hevia muestra que en ese punto los libertarios se equivocan, pero no muestra que tiene una teoría del derecho contractual diferente de la libertaria. Tampoco muestra que la teoría de la justicia libertaria sea incorrecta (solo que las críticas libertarias a Rawls no funcionan). Entonces, ¿qué debemos concluir del debate con los libertarios? A fin de cuentas, parece que todo el debate tiene poca incidencia para la teoría del derecho contractual.

${ }^{13}$ Kronman, A., Contract Law and Distributive Justice, Yale Law Journal, 1980. 
U\$S 1.000. No obstante, la intención o volición expresada en actos de este tipo tienen escaso valor moral. Kronman, por tanto, concluye que la justificación de los contratos no puede radicar meramente en el carácter deliberado de los actos de celebración. Afirma que es necesario algún criterio para distinguir los actos deliberados realmente voluntarios de los involuntarios, y ese criterio está dado por las formas aceptables e inaceptables en que los individuos pueden aprovecharse de su contraparte en el contrato. ¿Qué formas de aprovechamiento están justificadas? Kronman defiende que el principio de paretianismo, que es eminentemente distributivo, puede realizar la labor normativa que se requiere en la teoría del derecho contractual.

De acuerdo con el paretianismo, un acto concreto de aprovechamiento es aceptable si, y solo si, pertenece a la clase de actos que en el largo plazo mejoran la situación del explotado respecto del mundo en el cual ese tipo de aprovechamiento no está permitido. Es muy importante comprender que en un acto concreto el aprovechamiento puede perjudicar al explotado; pero, en la medida en que ese tipo de acto esté permitido por una regla que en el largo plazo incrementa los beneficios también de la persona perjudicada, el aprovechamiento termina siendo aceptable en el caso particular ${ }^{14}$.

La teoría de Kronman no es utilitarista, aunque su principio lleve un nombre que irremediablemente lo vincula con esta posición. Kronman mismo intenta distinguirse del utilitarismo, y explica que la maximización del bienestar general podría arrojar un resultado diferente del paretianismo cuando en las sociedades existen ciertos grupos bien identificados que siempre sufren los perjuicios de la explotación. Para el utilitarismo, ese perjuicio en el largo plazo puede quedar compensado por el amplio beneficio que obtienen los grupos aventajados de la comunidad. En segundo lugar, y todavía mucho más importante, en las transacciones "uno a uno" las formas más difundidas de utilitarismo recomiendan todo intercambio en el cual el excedente total sea positivo en el largo plazo y prohíben los intercambios con excedente negativo. El paretianismo, por el contrario, no permite 
que nadie se beneficie a costa de otro, pues están vedados los aprovechamientos que no mejoran a largo plazo la posición del explotado ${ }^{15}$.

La vinculación del paretianismo con el principio de Pareto es obvia. Según Pareto, el cambio de un estado social E1 a un estado E2 es recomendable si en E2 todos están mejor que en E1. Esta es la versión fuerte de Pareto. En la versión débil, el paso a E2 está recomendado si en E2 nadie empeora su situación respecto de E1, pero al menos una persona está mejor. El paretianismo parece garantizar que en el largo plazo ambas partes estarán mejor, ya que quien se aprovecha, evidentemente, obtiene beneficios de cada acto de aprovechamiento y, si se respeta el paretianismo, también el explotado en casos concretos termina estando mejor de lo que estaría si esos intercambios no se hubiesen permitido. Sin embargo, el paretianismo no es el principio de Pareto aplicado a las relaciones contractuales. Pareto exigiría contemplar el bienestar de toda la comunidad para evaluar si el paso de E1 a E2 está justificado por sus efectos positivos. Así, la validez del contrato entre Axileas y Xenofonte dependería de que luego de su celebración tanto los individuos como Axileas y Xenofonte vayan a estar mejor en el largo plazo si se permiten esos contratos, pero también de que individuos como Telémaco, Olympia y Perséfone, que no son parte del contrato, no empeoren su situación. Es decir, el principio de Pareto no limita el análisis a la clase de personas que consienten la obligación. El paretianismo de Kronman sí lo hace. Aplica al perjudicado un estándar que el mismo agente aceptaría racionalmente para regular sus interacciones privadas, pues es el que mejora sus perspectivas en el ciclo completo de vida.

Creo que esta reconstrucción es bastante fiel al pensamiento de Kronman. Hevia, por su parte, lo interpreta como si fuese un utilitarista y, por esta razón, sus objeciones son menos efectivas de lo que necesita para descartar al menos esta versión del distributivismo. En particular, Hevia atribuye a la teoría Kronman los siguientes defectos ${ }^{16}$ :

15 Ídem.

${ }^{16}$ Hevia, M., Reasonableness and Responsibility: A Theory of Contract Law. Dordrecht, Springer, 2013. 
La insoportable levedad de la justicia correctiva en el Derecho Contractual

i) La interacción contractual entre las partes es solo un medio para promover la justicia distributiva.

ii) No puede dar cuenta de la noción misma de obligación o vinculación contractual.

iii) Es incompatible con el efecto relativo de los contratos.

Los defectos enumerados como ii y iii están claramente relacionados. En realidad, se trata de la misma objeción presentada desde distintos puntos de vista. Hevia expone los problemas por separado, pero entiende que todos integran una misma objeción fundamental: Kronman es incapaz de explicar la bilateralidad de las interacciones privadas y, consiguientemente, la estructura normativa del derecho contractual. El hecho de que el consentimiento sea condición necesaria para obligar a ambas partes recíprocamente, y que nadie más que no haya consentido está vinculado por ese contrato, constituye el núcleo básico del derecho contractual que en el esquema de Kronman se torna ininteligible o misterioso.

Creo que el paretianismo tiene una fuerza mayor que la que Hevia le reconoce, y en breve mostraré cómo pueden eludirse las objeciones de Hevia. Antes permítanme analizar el defecto enumerado como $i$.

\section{IV.1. Los contratos son un mero instrumento distributivo}

Hevia puede tener buenas razones para atribuir a Kronman la idea de que los intercambios contractuales solo son un medio para realizar la justicia distributiva. En efecto, Kronman sostiene claramente que el derecho privado podría ser utilizado con fines redistributivos ${ }^{17}$.

${ }^{17}$ También sostiene que el carácter igualitario del paretianismo asume que todos los bienes pertenecen a un fondo común. Creo que esta afirmación de Kronman complica innecesariamente las cosas y puede justificar lecturas como la de Hevia. Así, es posible que las críticas que Hevia no sean incorrectas a la particular postura de Kronman, pero a fin de evaluar el enfoque distributivista debemos tomar la mejor versión posible; y, en mi opinión, ella excluye esta afirmación. Kronman, A., Contract Law and Distributive Justice, Yale Law Journal, 1980. 
En lugar de emplear exclusivamente el derecho tributario para lograr el ideal social en la distribución de los recursos, el derecho contractual podría estar diseñado para contribuir impidiendo ciertos estados distributivamente injustos que luego requerirían rectificación mediante la acción pública. El establecimiento de precios máximos o salarios mínimos son buenos ejemplos de este tipo de regulación ${ }^{18}$. Hay además una ventaja innegable al hacerlo de este modo, dado que la prevención de la distribución indeseable evita los costes de corregir la situación ex post.

Pese a todo, creo que esta tesis de Kronman, que no parece controvertida, puede distinguirse de su primera tesis según la cual el paretianismo es el principio que dota de fuerza normativa a la expresión de consentimiento. Es decir, una cosa es afirmar que el fundamento normativo del derecho de los contratos debe buscarse en las normas que regulan los intercambios de modo que los aprovechamientos recíprocos de las personas sean siempre aceptables, y otra muy distinta es afirmar que el derecho contractual podría ser diseñado para lograr ciertos objetivos sociales (distributivos, expresivos, de eficiencia, etc.). Hevia parece proyectar la segunda tesis de Kronman sobre la primera. Del hecho de que el derecho de los contratos pueda ser utilizado con fines distributivos, Hevia parece inferir que el paretianismo justifica los contratos solo en la medida en que contribuyan a alcanzar un estado social distributivamente justo. Pero esto sería un non sequitur. Como he dicho, el paretianismo simplemente determina qué actos de explotación son aceptables y esto es necesario, según Kronman, para que los efectos vinculantes del consentimiento tengan alguna plausibilidad moral. El paretianismo no puede indicarnos cuál es la distribución deseada a nivel social. Esa es una decisión política que debe ser adoptada en sede colectiva. Por tanto, la única relación que puede establecerse entre las dos tesis de Kronman es que ciertos contratos pueden ser prohibidos toda vez que interfieran con los objetivos distributivos de la comunidad. Por cierto, ello no equivale a afirmar que el derecho contractual está justificado por los patrones de distribución 
social que genera. Lo que se justifica por la distribución es una limitación a la autonomía de la voluntad. Ahora bien, las obligaciones que surgen de los contratos celebrados válidamente en ese esquema limitado por la justicia distributiva obtienen su fuerza moral del paretianismo, del hecho de que en el largo plazo incluso la parte explotada mejora su situación con una regla que permite el tipo de intercambio que él celebró. En ningún caso, la justificación de por qué Axileas debe la prestación a Xenofonte depende de que ello contribuya a un estado social distributivamente justo. La justificación de esa obligación en concreto depende de que la regla que impone el cumplimiento beneficie en el largo plazo al propio obligado, y no de que sea funcional a las políticas sociales.

En síntesis, Hevia atribuye a Kronman la tesis de que los contratos son un mero medio para realizar aspiraciones distributivas en el nivel social. Si esta lectura de Kronman fuese correcta, Hevia sin duda tendría razón en que la teoría difícilmente sea capaz de justificar la estructura bilateral del derecho contractual. He argumentado, en cambio, que para Kronman los contratos no son un instrumento de la distribución colectiva, aunque su plausibilidad moral depende de que no se permitan los aprovechamientos inaceptables de una parte sobre la otra. Asimismo, Kronman sostiene una segunda tesis, según la cual el derecho contractual puede ser utilizado con fines redistributivos. De estas dos tesis, se implica que los intercambios privados pueden ser limitados de modo que no obstaculicen el logro de objetivos sociales. Esta tesis derivada no pretende fundamentar la obligación contractual, sino justo lo contrario: la ineficacia del consentimiento para generar obligaciones contractuales. Al igual que los contratos que vulneran los derechos de terceros o que son celebrados bajo coacción son inválidos, también lo son aquellos que interfieren con la moral social o los objetivos políticos distributivos, expresivos, etc. No debería ser controvertido que el consentimiento privado puede ser limitado, y en todas las jurisdicciones que conozco este es el caso, por el llamado orden público. Más adelante, retomaré esta cuestión. 


\section{IV.2. El paretianismo y la estructura bilateral de los contratos}

Entre otras cosas, Hevia acusa al paretianismo de no poder explicar la importancia del consentimiento en la obligación contractual, ni el efecto relativo de los contratos. Respecto de lo primero, sostiene que no es claro por qué una posición como la de Kronman, asociada en su opinión con el criterio utilitarista de Pareto, debería negar el derecho de arrepentimiento al individuo que luego de celebrado el contrato experimenta un cambio de preferencias. Hevia plantea el problema en estos términos:

Suponga que A y B firman un contrato en virtud del cual B contrae un determinado deber con A. Imagine también que, en el momento en que el cumplimiento es debido, B se arrepiente de su decisión, digamos, porque le surgen nuevas oportunidades. A fin de determinar si la transacción es Pareto superior o no, debemos determinar qué conjunto de circunstancias han de tomarse en cuenta: si hemos de considerar el conjunto de preferencias previo o el nuevo. Ahora bien, ¿por qué debemos priorizar el acuerdo inicial a pesar del arrepentimiento? [...] Ciertamente, si estuviésemos preocupados por la satisfacción de preferencias - como parece ser el caso en las teorías de la eficiencia- elegiríamos respetar el segundo conjunto de preferencias por sobre el primero. Ello nos llevaría a excusar la mayoría de los incumplimientos contractuales. Pero la única diferencia entre estos dos conjuntos de preferencias es temporal, es decir, el mero hecho de que un conjunto antecede al otro. Necesitamos, entonces, algo que pueda explicar por qué, pese a su arrepentimiento, $\mathrm{B}$ debe algo a $\mathrm{A}$, o por qué no habría problemas en que $\mathrm{B}$ incumpliese su deber y aprovechase la nueva oportunidad. El estándar de Pareto, por sí mismo, no nos ayuda a resolver esta cuestión ${ }^{19}$.

${ }^{19}$ Hevia, M., Reasonableness and Responsibility: A Theory of Contract Law. Dordrecht, Springer, 2013. 
El punto que plantea Hevia en este párrafo es complejo y tiene un calado que excede la teoría del derecho contractual. En efecto, si el criterio de Pareto tuviese este problema, sería realmente inútil como estándar evaluativo. En este sentido, la mejor interpretación de la propuesta de Kronman, la más caritativa, no puede concebirlo como un utilitarista de acto que adhiere al criterio de Pareto, tal como asume implícitamente Hevia en su crítica. Por mi parte, ya he sostenido que no creo que Kronman sea un utilitarista, y mucho menos un utilitarista de acto. El pilar fundamental del paretianismo se ubica en la prevención de la explotación injustificada en el largo plazo, no en la maximización de la utilidad general o en las preferencias de las partes en cada caso concreto. La importancia del consentimiento, entonces, solo se justifica por aquella regla que respeta la libertad de las personas, entendida en los términos distributivos del paretianismo: nadie debe mejorar su posición mediante intercambios que en el largo plazo perjudican a su contraparte en el contrato. Con esto creo que es suficiente para cuestionar la efectividad del argumento de Hevia. Pero incluso un paretianismo de acto resistiría la existencia de un derecho general de arrepentimiento. Imaginemos que en el momento T1, el bienestar de Axileas y Xenofonte está representado por el punto $\alpha$ del siguiente gráfico.

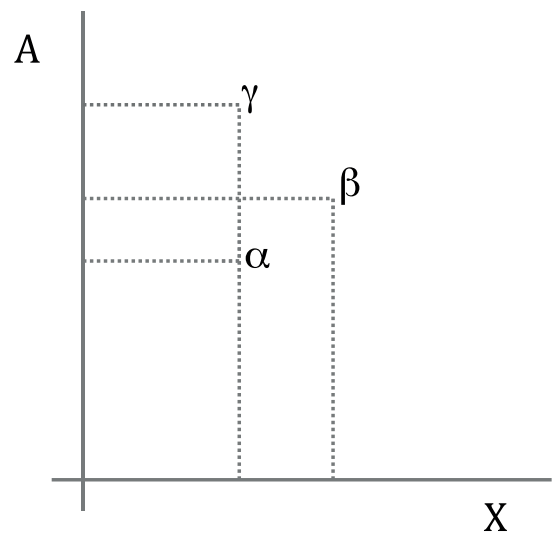


El derecho contractual en T1 permite a Axileas y Xenofonte transferirse mutuamente las obligaciones (de dar, hacer o no hacer) que, teniendo objeto lícito, consideren conveniente transferirse. Si ambos procuran desarrollar su plan de vida de manera que maximice sus posibilidades, solo intercambiarán las obligaciones que mejoren su situación. Supongamos, entonces, que celebran un contrato que los ubica en el punto $\beta$. Estando $\beta$ al noreste de $\alpha$, el intercambio ha sido eficiente, pues ha incrementado el bienestar de ambas partes. Así, el momento posterior a la celebración del contrato (T2) es preferido por Axileas y Xenofonte que el momento anterior (T1). El paretianismo de Kronman dirá que este contrato es válido porque las partes consintieron obligarse en unas condiciones distributivas moralmente defendibles: los dos mejoran con el acto y, por tanto, nadie explota al otro de manera indebida. La libertad genuina expresada en ese contrato va acompañada de la responsabilidad por los propios actos. Ello justifica el uso de la coacción estatal para hacer cumplir los términos acordados. Ahora, como sugiere Hevia, digamos que en T3, un momento posterior a la celebración de contrato pero anterior al cumplimiento, Axileas descubre que Telémaco le ofrece una oportunidad mejor, aunque incompatible con el cumplimiento del contrato que celebró con Xenofonte. Si Axileas incumpliese el contrato con Xenofonte y contratase con Telémaco, el bienestar de Axileas y Xenofonte se ubicaría en el punto $\gamma$. Nótese que el hipotético nuevo arreglo impuesto mediante el arrepentimiento beneficiaría a Axileas a costa de Xenofonte. La razón por la cual Xenofonte adquirió un crédito contra Axileas era que Axileas prestó su consentimiento y de esa manera cambió sus relaciones normativas de un modo admisible: transmitió a su contraparte un derecho sobre sus acciones futuras, un derecho que antes del contrato Xenofonte no tenía. Además, el consentimiento tiene fuerza vinculante porque en el mismo acto las partes obtuvieron un beneficio mutuo, por tanto, no hay una explotación indebida.

Para que tenga sentido afirmar que las personas son capaces de planificar su vida intercambiando sus recursos según su conveniencia, deben tener la autoridad normativa de tomar responsabilidad, y ello implica colocarse en una posición de vulnerabilidad frente a las 
pretensiones del otro. Si las partes no pudiesen ser demandadas por incumplimiento, entonces, perderían la facultad de obligarse mediante el contrato. La posibilidad de que Axileas pueda obligarse a realizar $\phi$ depende de que el derecho reconozca la fuerza moral del consentimiento. Para que exista la obligación contractual de hacer $\phi$, el consentimiento debe ser capaz de convertir a la acción $\phi$ en no optativa para Axileas, y ello supone que está justificado que su contraparte exija a Axileas que haga $\phi$, que sería adecuado criticar a Axileas por omitir $\phi$ cuando se comprometió a ello, etc. La única restricción que impone el paretianismo a estas ideas es que la facultad de los individuos para obligarse se limita a los intercambios que mejoran su bienestar ${ }^{20}$. Para el paretianismo, es irrelevante que las preferencias de las partes cambien luego de la celebración del contrato. El pacto al que han llegado ha modificado sus relaciones normativas de un modo admisible (es decir, sin explotación), y el nuevo mundo normativo, posterior a la celebración del contrato, solo puede ser alterado por las partes mediante un consentimiento también distributivamente plausible, o por razones de orden público (nulidades, causas legales de rescisión o resolución, imprevisión, frustración del fin del contrato, etc.).

Veamos ahora si el paretianismo puede dar cuenta del efecto relativo de los contratos. Dice Hevia:

${ }^{20}$ Dos aclaraciones son importantes. En primer lugar, los contratos gratuitos también mejoran la posición de las partes en un sentido relevante, pues muchas veces el bienestar de una persona depende del bienestar de otra. En segundo, esta tesis no afirma que los individuos siempre obtengan beneficios en todos los contratos que celebran. En ocasiones, las personas erran en sus estimaciones o simplemente ven alteradas sus preferencias a poco de celebrado el contrato. Esto no afecta al paretianismo como teoría, ya que al momento de contratar las partes mejoraron su situación, en tanto adquirieron unas perspectivas que antes no tenían. Que las perspectivas se frustren en algún grado no muestra que el contrato en realidad era poco ventajoso. Tal como era el mundo en T1, el contrato podría haber sido la mejor alternativa para ambos. Siempre y cuando el error o la frustración posterior no superen cierto umbral, el contrato es válido en la mayoría de los ordenamientos jurídicos. 
Supongamos un caso en que hemos determinado que está permitido que A obtenga una ventaja de B y, por tanto, hemos establecido que mediante su interacción $B$ tiene un deber respecto de $\mathrm{A}$. En este contexto, si $\mathrm{B}$ incumple su deber, no es necesariamente el caso que él deba compensar a A. Según el principio paretiano, si la víctima de un incumplimiento tiene derecho a ser compensada, no es claro quién tiene el deber correlativo de proveer la indemnización. Podría ser el caso que, de acuerdo con el principio de Pareto, C, D o E estén en mejor posición de asumir la responsabilidad por el incumplimiento de $\mathrm{B}$. Esto es problemático precisamente porque ni $\mathrm{C}, \mathrm{D}$ o $\mathrm{E}$ tenían un deber contractual con $\mathrm{B}$. El principio paretiano no puede acomodar el hecho de que si solo A y B son parte del contrato, su acuerdo no es vinculante para terceros como C, D o E, quienes no intervienen en la transacción. Además, no puede explicar el hecho de que, en el marco de las interacciones bilaterales, la parte que incumple, y nadie más, debe tener la responsabilidad de compensar a la víctima del incumplimiento. De acuerdo con la concepción de Kronman, simplemente no hay razones para limitar la clase de los demandados y los actores a los promitentes que incumplen y las víctimas perjudicadas. Asimismo, para Kronman, el promitente y el beneficiario de la promesa no parecen tener ninguna relación normativa importante entre sí: lo que parece importar es su relación con el ideal distributivo ${ }^{21}$.

Aquí Hevia reproduce la crítica de la bilateralidad que autores como Jules Coleman y Ernest Weinrib han dirigido con incuestionable éxito contra el análisis económico del derecho ${ }^{22}$. La objeción resulta efectiva, en realidad, contra cualquier teoría agregativa, ya sea económica o no económica. El problema es que Kronman no es un partidario de la escuela económica, ni sostiene una visión agregativa

${ }^{21}$ Hevia, M., Reasonableness and Responsibility: A Theory of Contract Law. Dordrecht, Springer, 2013.

${ }^{22}$ Coleman, J. L., "The Structure of Tort Law", en Yale Law Journal, 1988, Weinrib, E., "Understanding Tort Law", en Valparaiso University Law Review, 1989. 
de los contratos. Sin importar cuán cercano sea al principio de Pareto, el paretianismo es un principio distinto del empleado por la teoría económica. A la vez, con independencia del énfasis que coloca Kronman sobre la distribución, el paretianismo es claramente distinguible de las teorías de la justicia distributiva que establecen patrones (que es el tipo de distribución que Hevia toma en cuenta para formular su objeción). Veámoslo.

Hevia sostiene que una vez que dos individuos celebran un contrato y uno incumple, no es claro quién tiene el deber de compensar a la víctima del incumplimiento. Si Axileas incumple su contrato con Xenofonte, el derecho contractual impone a Axileas el deber de indemnizarlo. Pero, argumenta Hevia, conforme con el principio de Pareto, es posible que la distribución global mejore cuando es Telémaco o Perséfone quien tiene el deber de compensar. Evidentemente, Hevia está pensando en un principio diferente del criterio de Pareto. Recordemos que de acuerdo con Pareto, un cambio social es eficiente o recomendable solo si mejora la posición de todos los involucrados (o mejora a algunos sin empeorar a nadie). Pues bien, ¿cómo la obligación de compensar podría mejorar (o no empeorar) a Telémaco o a Perséfone, quienes al no ser parte del contrato tampoco obtuvieron los beneficios de la transacción? No existe posibilidad lógica de imponer la obligación de indemnizar a un tercero sin a la vez perjudicarlo. Por lo tanto, el criterio de Pareto objetaría la imposición de la obligación de compensar a alguien diferente de la contraparte del contrato. E1 paretianismo, no el criterio de Pareto, también resuelve la cuestión del mismo modo. Si el contrato fue válidamente formado, entonces, no hubo aprovechamiento indebido. Si no hubo aprovechamiento indebido, entonces, el consentimiento tiene fuerza moral suficiente para obligar a las partes. De ahí se sigue que Kronman presupone que los contratos solo obligan a quienes consienten. Los terceros pueden tener obligaciones no contractuales respecto de algunas de las partes del contrato, mas no obligaciones que por su naturaleza requieren de consentimiento. Sin embargo, Kronman no cree que tenga sentido hablar de "consentimiento" sobre lo que es injustificable que alguien acepte. Y por ello impone restricciones distributivas a lo que se puede 
consentir. Ahora bien, si el tipo adecuado de consentimiento tiene plausibilidad moral, y solo el consentimiento adecuado puede fundar las obligaciones contractuales, ¿cómo podría un contrato obligar a un tercero que no ha consentido?

Hevia tiene en mente, creo yo, las teorías estáticas de la justicia distributiva, para las cuales el consentimiento es puramente instrumental al patrón distributivo deseado socialmente y puede ser desechado cuando no promueve ese patrón. Por esta razón, piensa que Telémaco o Perséfone podrían estar en mejores condiciones que Axileas para indemnizar a Xenofonte. No obstante, este tipo de consideraciones son incompatibles con el paretianismo de Kronman e incluso con el criterio de eficiencia paretiano, que exige que nadie empeore su situación con ningún cambio social. La reconstrucción de Hevia priva al consentimiento de toda significación moral en la teoría de Kronman, dado que el contrato puede obligar incluso a quien no consintió. Pero ello va en contra del propósito que explícitamente se propone lograr Kronman: definir las condiciones en las cuales el consentimiento (no la distribución general) justifica la fuerza vinculante de los contratos. Por tanto, el paretianismo no puede traer como consecuencia la obligatoriedad de los contratos para terceros que no participan de la interacción; y, si esto es así, el paretianismo puede dar cuenta perfectamente del efecto relativo de los contratos.

\section{Segundo argumento distributivo: el carácter público del derecho privado}

En este apartado no pretendo defender el paretianismo de Kronman, sino elaborar un argumento más general a favor del monismo que sea inmune a las objeciones de Hevia. Explica Hevia que de acuerdo con el monismo los principios empleados para evaluar la justicia de las instituciones son los mismos que se aplican a la conducta privada de los ciudadanos. El ejemplo más conocido de este tipo de teorías es el utilitarismo. Para esta corriente, la pregunta referida a cómo debemos actuar en cada caso concreto no tiene una respuesta distinta de la pregunta relativa a cómo debemos diseñar nuestras instituciones 
sociales básicas. En ambos casos, debemos intentar maximizar el bienestar social en el largo plazo. Siguiendo a Liam Murphy, Hevia sostiene que para el monismo hay un continuo entre el dominio normativo privado y el dominio normativo público, y la separación entre ambos está justificada porque los individuos enfrentamos deficiencias cognitivas serias al momento de calcular los efectos de nuestras decisiones particulares. Si tuviésemos una capacidad mayor para prever cuáles serán las consecuencias distributivas de nuestras acciones, entonces, tendríamos la obligación de aplicar los mismos principios morales que rigen el diseño de las instituciones. Evidentemente, el monismo tiene una fuerte confianza en la deliberación colectiva, puesto que asume que el diseño de las instituciones sí puede estar guiado por el ideal de justicia distributiva, en cambio, los individuos, aun los de buena fe, son incapaces de guiar su vida tomando los mismos principios como pauta de comportamiento.

A partir de aquí, Hevia concluye que según el monismo no es claro que debamos tener un derecho contractual como el que tenemos. Dice:

Nuestra decisión de tener o de no tener derecho contractual dependerá de información empírica contingente acerca de cuál es el mejor modo de cumplir con nuestros objetivos distributivos. En caso de que consideráramos necesario tener derecho de los contratos, tendríamos que diseñar sus reglas de un modo tal que, en última instancia, estas promuevan nuestra concepción de la justicia distributiva. [...] El punto central de Murphy puede resumirse del siguiente modo: para él, no existen los contratos genuinamente privados porque, en el fondo, cualquier contrato es un modo de promover la justicia distributiva ${ }^{23}$.

¿En qué sentido los contratos son genuinamente privados para Hevia? Sin duda, incumplir un contrato no es como incumplir una simple promesa. Se parece bastante, en tanto quien incumple un contrato hace algo que también es incorrecto para quien cree que

${ }^{23}$ Hevia, M., "Razonabilidad y responsabilidad: Rawls, Kant y la teoría del derecho contractual", Discusiones, XV, 2014, págs. 15-47. 
se deben cumplir las promesas ${ }^{24}$. Pero los contratos no son meras promesas, pues el incumplimiento de un contrato justifica el uso de la coerción estatal, mientras que esto no ocurre con el incumplimiento de cualquier promesa ${ }^{25}$. La obligación de cumplir con una promesa no contractual forma parte de la moral privada. Es plausible asumir que existe un conjunto de principios morales que se aplican a los individuos, pero que no justifican la coerción del estado. Por ejemplo, ¿debe dejar de fumar un padre que promete a sus hijos que dejará de fumar?, ¿debe uno preocuparse por el bienestar de sus amigos en el mismo grado en que ellos se preocupan por el bienestar de uno?, ¿debe uno cultivar la amistad o debe solo entablar relaciones basadas en el puro interés económico o estratégico?, ¿debe uno formar una familia?, ¿es incorrecto mantener una relación sentimental asimétrica para no estar solo mientras se busca una pareja que realmente colme sus expectativas?, ¿debe uno hacer caridad o satisface sus obligaciones morales relativas al bienestar de otros si lleva sus impuestos al día? Me inclino a pensar que algunas de estas cuestiones tienen una respuesta correcta en materia moral, pero en ningún caso se entiende justificado que el Estado imponga forzosamente estos principios. Estos asuntos son estrictamente privados.

A diferencia de las cuestiones recién mencionadas, la obligatoriedad de cumplir con un contrato y su correspondiente ejecución en los tribunales tienen un componente público. Ello es así porque pretendemos que todo el derecho, aun el que está diseñado para que los particulares ordenen sus relaciones de manera privada, sea públicamente justificable. Si hemos de aplicar la fuerza del Estado para hacer cumplir los términos acordados por las partes, debemos asegurarnos de que esos términos satisfagan un mínimo de justicia. Por consiguiente, sea cual fuere la forma de justicia que está implementada en el derecho privado, ella tiene una dimensión pública. Con esto quiero decir que la validez del contrato entre Axileas y Xenofonte,

${ }^{24}$ Fried, C., Contract as Promise. A Theory of Contractual Obligation, CambridgeMass, Harvard University Press, 1981.

${ }^{25}$ Barnett, R., Some Problems with Contract as Promise, Cornell Law Review, 1992. 
su fuerza vinculante, no depende exclusivamente de que Axileas y Xenofonte lo acepten de forma voluntaria (ejerciendo una libertad moralmente defendible). Qué contratos son válidos y cuáles no, cuál será el remedio en caso de incumplimiento, qué tipo de responsabilidad (por culpa u objetiva) es aplicable a cada caso, todo ello debe ser decidido en la arena pública. En efecto, si el derecho contractual fuese una cuestión estrictamente privada, no se entendería por qué ciertos contratos que no afectan los derechos de terceros son, de todas formas, jurídicamente inválidos.

Siendo esto así, existe el mundo de lo privado y el mundo de lo público. El derecho siempre pertenece al mundo de lo público. ¿Cómo podría ser una cuestión privada la ejecución compulsiva de un contrato si el demandante pide al Estado que emplee la coerción contra el demandado? Sin embargo, el derecho reconoce que existen ámbitos en los cuales la autonomía de la voluntad tiene más presencia que en otros. En el derecho penal la autonomía de la voluntad es muy restringida, y en el derecho contractual suele ser más bien amplia. Parece que el derecho privado tiene ese nombre (derecho privado) porque pretende expresar la idea de que el resultado final en la asignación de castigos (mediante cláusula penal en los contratos y los daños punitivos en la responsabilidad extracontractual, por ejemplo) y la distribución de recursos (mediante la negociación) quedará librado a la ordenación espontánea de los particulares. Dado que las partes pueden decidir autónomamente contratar o no contratar, con quién contratar, sobre qué objeto, a qué precio y, también, pueden disponer libremente de la acción por incumplimiento, serán los mismos particulares quienes determinarán la asignación final de algunos recursos.

La dimensión pública del derecho contractual no puede ser negada sin asimilar las obligaciones que surgen de los contratos a otro tipo de obligaciones que surgen de prácticas morales informales, como las promesas o las relaciones de confianza en grupos reducidos de cooperación iterada, u otros principios de la moral privada. Ahora bien, si el monismo negase esto sería una postura muy implausible. En cambio, 
lo que el monismo puede negar es que exista una pluralidad de principios públicos de justicia: justicia hay una sola, y es distributiva ${ }^{26}$.

A favor de esta postura puede decirse que no es claro el estatus de un principio como la justicia correctiva, que pretende ser privado a la vez que reclama un reconocimiento y respaldo público. Es cierto que cuando Xenofonte demanda a Axileas por incumplimiento contractual, en el litigio no se discute, ni el tribunal considera, nada relativo al objeto de una distribución, ni al criterio con que se repartirán los costes del incumplimiento. La decisión judicial no tiene los atributos típicos de una distribución. Más bien, se discute la incorrección de la acción, la relación de causalidad con el perjuicio sufrido por el demandante y la magnitud de la pérdida reclamada. En tanto pueda establecerse que el agente infringió un deber correlativo con un derecho de su contraparte, el análisis del caso transita los carriles habituales de la justicia correctiva, dado que la pretensión es que se rectifique el incumplimiento de las obligaciones que uno tenía respecto del otro. Pese a ello, ¿cuál es la justificación para que el Estado reconozca el valor normativo de la justicia correctiva?

Bien, en una teoría de la justicia distributiva dinámica, como la que asume Hevia siguiendo a Rawls, la responsabilidad personal por las consecuencias de las propias decisiones es un elemento esencial, ya que es lo único que hace posible que los sistemas sean de justicia procedimental pura, y esto último es importante para que las aspiraciones distributivas no coarten la libertad individual. Recordemos que para Rawls, una vez que las personas tienen garantizados ciertos bienes básicos, la asignación de recursos que resulta del ejercicio de su libertad es justa. En este sentido, los individuos pueden contratar unos con otros y, como son responsables de sus propios asuntos, es irrazonable que objeten el resultado distributivo de esas operaciones. Así, parece que la justicia correctiva, que hace responsables privadamente

${ }^{26}$ Aunque no es la estrategia que estoy siguiendo en este apartado, existen argumentos conceptuales para poner en duda la distinción entre justicia correctiva y justicia distributiva. Véase Gardner, J., "Justicia correctiva" (corr.), en Papayannis, D. M. (de.), Derecho de daños, principios morales y justicia social. Madrid-Barcelona-Buenos Aires, Marcial Pons, 2013. 
a las partes, es necesaria para la realización plena de la justicia distributiva. Por consiguiente, el derecho contractual con sus remedios característicos ante el incumplimiento es una parte de la justicia distributiva, entendida dinámicamente. En un orden liberal, los individuos pueden asociarse y planificar su vida juntos, emprender proyectos en común, intercambiarse bienes según su conveniencia, beneficiarse gratuitamente incluso, si ello mejora sus perspectivas, entre muchas otras facultades. Todo esto requiere que exista un derecho contractual similar al que conocemos, pero la justificación última de esta institución es pública y distributiva. A fin de que las personas sean responsables de cómo resulta su vida una vez que reciben una cuota equitativa de bienes primarios, los contratos deben generar obligaciones y derechos correlativos para las partes. Si Axileas contrata con Xenofonte, a nadie más que a su contraparte puede exigir que cumpla con el contrato y nadie más tiene derecho a demandar con base en él. La introducción de terceros que no forman parte del contrato alteraría el procedimiento distributivo, de acuerdo con el cual las personas son responsables de la distribución resultante cuando operan con un trasfondo en el cual la distribución es justa.

Supongamos que Axileas incumple su contrato con Xenofonte y que el sistema jurídico otorga a Xenofonte un derecho de exigir la prestación a un tercero que no formó parte de él, digamos Telémaco (o el Estado mismo). En ese caso, Axileas no estaría tomando responsabilidad por sus actos, puesto que su compromiso sería saldado en última instancia por Telémaco. Al mismo tiempo, si Xenofonte tuviese derecho a demandar a cualquier otra persona cuando su contraparte incumple, tampoco estaría tomando responsabilidad por sus decisiones. Él decidió contratar con Axileas, y debió tener en cuenta su seriedad, su patrimonio, su fiabilidad, etc. Si Xenofonte pudiese quedar cubierto con independencia de que Axileas cumpla, entonces, no estaría asumiendo la responsabilidad ligada al hecho de que él eligió contratar con Axileas y no con Telémaco o con el Estado. Tampoco estaría asumiendo la responsabilidad de no tomar un seguro contra el incumplimiento. Asimismo, si alguien distinto de Xenofonte pudiese exigir a Axileas el cumplimiento del contrato se 
estaría interfiriendo en la decisión de Xenofonte de no demandar a Axileas y de ese modo beneficiarlo. Una parte importante del orden privado, dije, es que los individuos pueden decidir a quién beneficiar con sus acciones. La intervención de un tercero, en este caso, estaría coartando la libertad de Xenofonte de liberar a su contraparte.

En toda esta explicación, no parece haber ninguna razón realmente privada capaz de justificar que el Estado haga cumplir forzosamente los términos acordados por las partes; más bien, parece haber una razón pública detrás de ello: la división de la responsabilidad es esencial para que el sistema implementado sea de justicia procedimental pura y, por tanto, compatible con la libertad individual. En conclusión, el principio de división de la responsabilidad al que adhiere Hevia tiene un fundamento distributivo y, por ello, mal puede separar las aguas de la justicia distributiva y la justicia correctiva, como piensa Ripstein ${ }^{27}$. Dividimos la responsabilidad y reconocemos que ciertos reclamos son un asunto que deberán gestionar los privados con la asistencia pública mínima de los tribunales y los agentes de seguridad solo por razones distributivas $^{28}$.

\section{Tercer argumento distributivo: la insuficiencia de la justicia correctiva}

De inicio, Hevia afirma que las reglas del derecho contractual deben ser entendidas en términos de justicia correctiva y no en términos de justicia distributiva ${ }^{29}$. Dejemos de lado los argumentos anteriores y asumamos, como Aristóteles, que la justicia correctiva y la justicia distributiva son dos principios mutuamente irreductibles. Digamos que son dos formas de justicia conceptual y normativamente independientes. Aun en este caso, la mayoría de las reglas del derecho

${ }^{27}$ Ripstein, A., The Division of Responsibility, Fordham Law Review, 2004.

${ }^{28}$ Ahora puede advertirse que mi argumento no pretende negar la distinción entre justicia correctiva y justicia distributiva, sino solo que el principio de división de la responsabilidad sea suficiente para trazarla.

${ }^{29}$ Hevia, M., Reasonableness and Responsibility: A Theory of Contract Law. Dordrecht, Springer, 2013. 
contractual no pueden ser explicadas como una cuestión de justicia correctiva. La justicia correctiva ordena rectificar las interacciones injustas, aquellas en las que una parte vulnera los derechos de la otra $^{30}$. Es un principio subsanador y, por su naturaleza, presupone una distribución de derechos previa. Solo pueden ser vulnerados y rectificados los derechos que han sido definidos con un principio independiente de la justicia correctiva. Para que el derecho de los contratos sea una institución privada, entonces, los términos del intercambio válido deberían establecerse exclusivamente por la voluntad de las partes. Pero la autonomía de la voluntad tiene un protagonismo cada vez menor en el contrato moderno. La contratación masiva, mediante formularios predispuestos y condiciones generales de contratación, se ha impuesto sobre el contrato discrecional ${ }^{31}$, e incluso los contratos discrecionales están fuertemente regulados por normas de orden público. En este sentido, gran parte de los derechos que tienen las partes en una relación contractual no dependen de su voluntad, es decir, no han sido creados por la autoridad normativa de los individuos ni cuentan ellos con la potestad de dejarlas de lado. Entonces, ¿cómo podría la justicia privada explicar este conjunto de derechos y deberes?

El modelo de Hevia parece detenerse en la abstracción que impulsaba el primer movimiento codificador francés. Al presentar el primer proyecto de código civil en 1793, Cambacérès manifestó que debían satisfacerse las necesidades del hombre en la sociedad: ser dueño de sí mismo, contar con bienes suficientes para llevar adelante su vida y poder disponer de esos bienes en su propio interés ${ }^{32}$. Estas ideas coinciden en lo fundamental con la concepción de la justicia liberal que expone Hevia en términos de una división de la responsabilidad entre

${ }^{30}$ El contenido del principio de justicia correctiva es sumamente controvertido entre los filósofos. Aquí utilizo una formulación muy simple que se ajusta a la caracterización de Hevia, M., Reasonableness and Responsibility: A Theory of Contract Law. Dordrecht, Springer, 2013.

${ }^{31}$ Rezzónico, J. C., Contratos con cláusulas predispuestas, Buenos Aires, Astrea, 1987.

32 Bobbio, N., El positivismo jurídico, Madrid: Debate, 1998. 
los individuos y la sociedad. Los ideales de libertad e igualdad que inspiraron la Revolución francesa requerían un conjunto de normas muy simples que garantizasen 1) ciertos derechos de propiedad bien definidos; 2) una buena cuota de libertad personal, de modo que cada uno pueda poner su fuerza de trabajo al servicio de su plan de vida, y 3) un derecho contractual, también muy simple, para maximizar la asignación de los recursos y las posibilidades de acción conjunta. En este marco, el derecho contractual está prácticamente dominado por la autonomía de la voluntad. El art. 1134 del Código de Napoleón establecía la norma de oro que fue replicada luego en la mayor parte del derecho continental: "Los contratos legalmente concluidos tienen fuerza de ley entre las partes que los han celebrado" 33 . El único límite para la autonomía de la voluntad se encontraba en una serie de normas relativas a los vicios del consentimiento (error, dolo, violencia o intimidación) y en el orden público que hace ilícita la contratación sobre ciertos objetos (objeto inmoral o contrario a las buenas costumbres, cosas que están fuera del comercio, etc.).

En este marco, la teoría de Hevia funciona perfectamente. Tanto la regla de oro como los remedios ante el incumplimiento pueden ser comprendidos a la luz de los principios que regulan las interacciones privadas. Pero el derecho contractual moderno está altamente regulado. La mayoría de las cláusulas no son producto de la negociación de las partes. En ciertos contratos, como los de provisión de servicios públicos domiciliarios, el consumidor puede poco más que decidir contratar o no contratar, y la empresa proveedora ni siquiera puede decidir no contratar ${ }^{34}$. Salvo que existiese alguna causa de orden público que le autorice a no prestar el servicio, está obligada a proveer cada vez que un consumidor lo requiere. Todas las condiciones en que se presta el servicio, incluyendo el precio, están establecidas de antemano por un ente regulador. Las partes solo pueden adherir a las modalidades previstas. Uno podría pensar que este nivel

${ }^{33}$ En el derecho argentino, esta norma está expresada en el art. 1197 del Código Civil.

${ }^{34}$ Sobre la llamada obligación de contratar y sus condiciones, véase Alterini, A. A., Contratos. Buenos Aires, Abeledo-Perrot, 1998. 
de regulación se debe a que en general los servicios públicos domiciliarios son monopolios naturales, y ello exige que el Estado establezca las condiciones de provisión del servicio. Pero otros contratos, como el contrato de seguro, tienen lugar en un contexto competitivo, y no por ello la regulación es más sencilla ${ }^{35}$. Las leyes sobre contrato de seguro suelen restringir fuertemente la autonomía de la voluntad. Estas intervenciones están justificadas en tanto se asume que los sistemas de seguros también abordan un problema social: gestionar los riesgos de modo que los ciudadanos cuenten con un nivel razonable de indemnidad y estabilidad en su bienestar personal.

Hevia no puede decir que estos contratos no son genuinos contratos. Una vez formalizados, la estructura de derechos y deberes es perfectamente bilateral. El documento contractual establece cláusulas que las partes no pudieron modificar y, sin embargo, ellas establecen derechos y deberes recíprocos, exclusivamente exigibles a la contraparte. Es decir, al igual que en cualquier contrato, las partes están vinculadas normativamente entre sí, y solo entre sí. El efecto relativo de los contratos también es una característica esencial. No obstante, estas reglas que forman la mayor parte del derecho contractual moderno no pueden ser explicadas por la justicia correctiva. Mi idea, obviamente, es que son una cuestión de justicia distributiva.

Como dije, esta no es una característica exclusiva de la contratación masiva. La limitación de la autonomía de la voluntad en el derecho moderno operó progresivamente. En el derecho argentino, por ejemplo, el primer gran cambio tuvo lugar con la reforma del Código Civil en el año 1968, aunque la jurisprudencia anterior ya anticipaba muchas de las "novedades". En lo que hace a los contratos, el eje de la reforma está conformado por la introducción de la lesión subjetiva-objetiva (art. 954 CC), el abuso de derecho (art. 1071 CC) y la imprevisión (art. 1198 CC). Sin entrar a analizar cada figura, puede apreciarse fácilmente que los tres institutos tienen algo en común: intentan preservar la equivalencia de las prestaciones, y esta es una

${ }^{35}$ Alterini, A. A. y López Cabana, R., La autonomía de la voluntad en el contrato moderno. Buenos Aires, Abeledo-Perrot, 1989. 
preocupación distributiva. Por cierto, para que haya un intercambio con sentido, las partes deben estimar que aquello que reciben es más valioso para su plan de vida que aquello que dan a cambio. Pero el derecho intenta evitar que mediante el contrato se obtenga algo mucho más valioso de lo que se cede a la contraparte, y el criterio para juzgar el valor ya no es subjetivo, relativo a cada plan de vida, sino objetivo. En la mayoría de los casos, el control racional de la equivalencia depende de que exista un precio de mercado por el bien o servicio intercambiado. Más allá de las dificultades para estimar el valor objetivo de las prestaciones, es claro que el propósito de estas normas es vedar la explotación y, en algunos supuestos, poner un límite a la inequidad distributiva. Es decir, el derecho no se preocupa meramente por prevenir el aprovechamiento, puesto que un contrato que mejora a ambas partes, que es Pareto superior, también puede ser anulado si implica un desequilibrio importante. Conforme con el art. $954 \mathrm{CC}$, el contrato puede ser anulado o revisado si una de las partes, aprovechando la necesidad, la inexperiencia o la ligereza de la otra, obtiene una ventaja desproporcionada, aunque el sujeto explotado al momento de contratar haya preferido la situación poscontractual de explotación antes que el estado del mundo en la cual el contrato no se celebra. Esta limitación de la autonomía de la voluntad solo puede entenderse apelando a los principios de la distribución justa en los intercambios contractuales ${ }^{36}$. Lo mismo vale respecto del llamado ejercicio abusivo del derecho de contratar, mediante el cual se prohíbe la imposición de cláusulas que perjudican a la otra parte sin que se aprecie una razón o un beneficio compensatorio en otro aspecto del contrato. En lo que hace a la teoría de la imprevisión, la norma pretende evitar

${ }^{36}$ En consonancia con la postura de Kronman, algunos autores señalan que "el consentimiento debe ser valorado con prolija minuciosidad a fin de poder darle viabilidad jurídica plena al negocio que se ha concretado". Esto supone adherir claramente a una tesis de acuerdo con la cual el consentimiento es normativamente significativo solo en el marco de las interacciones que generan una distribución justa entre las partes. Véase Zago, J. A., El consentimiento en los contratos y la teoría de la lesión, Buenos Aires, Editorial Universidad, 1981. 
que una parte se empobrezca excesivamente cuando una contingencia no anticipada supera cierto umbral de onerosidad. En principio, las partes al negociar un contrato acuerdan un precio teniendo en cuenta los riesgos futuros. Cada uno debe considerar la posibilidad de que haya variaciones en el coste de producción, de que se modifique la estructura del mercado, de que aparezcan nuevas oportunidades que hacen inconveniente cumplir con el contrato, de que cambien sus preferencias, etc. Los riesgos de esta naturaleza corren a cargo de cada una de las partes, pues la idea misma de celebrar un contrato es que la palabra empeñada es inmune frente a estas contingencias. Pero si el riesgo que se concreta no estuvo específicamente previsto (y, por lo tanto, no estaba contemplado en el precio) y ello hace que la prestación devenga excesivamente onerosa, en tanto supone un desequilibrio distributivo severo, el derecho suele otorgar a la parte afectada la facultad de solicitar la resolución del contrato. No veo cómo estas restricciones pueden ser interpretadas sin referencia a la justicia distributiva. En definitiva, estas normas no pueden ser explicadas por la justicia privada, por dos razones: a) porque resultan aplicables con independencia de la voluntad de las partes; b) porque conforman el trasfondo en el cual ciertas interacciones están permitidas.

La cuestión es todavía más clara en las leyes de defensa del consumidor. En el derecho argentino, la Ley 24.240 y sus enmiendas posteriores asumen que el presupuesto inicial es la desigualdad de las partes, no su igualdad. Estas leyes vienen a proteger a la "parte débil" del contrato, que ya no consiente sino que asiente, adhiriendo a los términos del intercambio preconcebidos por el oferente. Entre las medidas protectoras, por mencionar algunas, se encuentra un sólido deber de información a cargo del oferente (art. 4 LDCU), cuyo incumplimiento conlleva la obligación de compensar los perjuicios causados e incluso la posibilidad de solicitar la anulación total o parcial del contrato, según el caso (art. 37 LDCU); un plazo mínimo de garantía obligatoria (es decir, irrenunciable), durante el cual todo gasto de traslado necesario para proceder a la reparación del bien en cuestión corre a cargo del vendedor (art. 11 LDCU); el establecimiento de un período de reflexión para las ventas realizadas fuera del establecimiento 
comercial, en cuya vigencia el consumidor puede revocar su aceptación sin coste alguno de su parte (arts. 32 a 34 LDCU); la tipificación de cláusulas abusivas, cuya consecuencia es que se las tiene por no escritas (art. 37 LDCU); y el reconocimiento de estándares de diligencia distintos para consumidores y profesionales (art. 18.b LDCU). Todas estas normas guardan una gran coherencia bajo el presupuesto de que el oferente es un profesional y el consumidor un profano.

Los arts. 37 y 18 son especialmente esclarecedores. De conformidad con el art. 37, sin perjuicio de la validez del contrato, se declara la nulidad de pleno derecho de diversas cláusulas, como aquellas que desnaturalizan las obligaciones ${ }^{37}$, las que limitan la responsabilidad por daños, las que importan una renuncia o restricción de derechos del consumidor, o las que invierten la carga de la prueba en perjuicio del consumidor. Asimismo, las cláusulas vagas o ambiguas deben interpretarse del modo más favorable para el consumidor. Los efectos distributivos de estas disposiciones son innegables más allá de su conveniencia ${ }^{38}$.

En cuanto al art. 18, muchas veces se pasa por alto que en combinación con otras normas produce efectos progresivos al atenuar el deber de diligencia a cargo del consumidor. Piénsese que el juego de los arts.

${ }^{37}$ La doctrina ha entendido que se trata de una amplia gama de cláusulas que quiebran la equivalencia en las prestaciones de las partes. Véase Alterini, A. A., Contratos. Buenos Aires, Abeledo-Perrot, 1998.

${ }^{38}$ Creo que es natural entender que todas estas normas son explicables por la justicia distributiva y no por la justicia correctiva o privada. No obstante, podría cuestionarse la conveniencia de algunas de ellas. Así, por ejemplo, es sabido que la obligación de ofrecer un plazo mínimo de garantía puede en ciertos contextos incrementar los precios de los productos y servicios, por lo tanto, el beneficio neto para los consumidores como clase es incierto, sobre todo cuando algunos de ellos no tengan la capacidad económica de adquirir los bienes a su nuevo precio. Lo mismo ocurre con la prohibición de limitar la responsabilidad por daños. El oferente simplemente contratará un seguro y trasladará ese coste adicional al precio. En general, puede esperarse que estas medidas sean positivas por varias razones, como la dispersión entre todos los consumidores del coste de la compensación, entre otras cosas. Pero aquí solo quiero señalar el aspecto distributivo de estas normas, con independencia de su sabiduría distributiva. 
4, 18 y 37 hace que el consumidor no tenga el deber de conocer las características básicas del producto que está adquiriendo, pues en caso de no ser informado al respecto tendrá la facultad de exigir la nulidad total o parcial del contrato. En cambio, según el régimen general del Código Civil, el error que se produce por negligencia del adquirente no puede ser alegado para anular el contrato (art. 929 CC). A la vez, en lo que hace a los vicios redhibitorios, el proveedor no puede alegar que el consumidor, por su profesión, los conocía o debía conocerlos. La ley permite al consumidor aquello que el Código Civil impide a los profesionales: demandar por los vicios ocultos que debido a su oficio estaban al alcance de su conocimiento. Así, el art. 18 inc. b. LDCU establece un estándar diferente, ya que el mismo profesional, que tiene el deber de conocer, en ciertos casos deja de tenerlo si actúa como consumidor. Los teóricos de la justicia correctiva siempre han negado la posibilidad de que el estándar de diligencia sea variable según las particularidades de los agentes o la posición que ocupen en el mundo. Ello atenta contra la igualdad formal que la justicia privada intenta preservar $^{39}$.

En suma, todas estas normas reseñadas muestran que una parte esencial del derecho contractual solo puede ser explicada por la justicia distributiva, no por la justicia correctiva. En el esquema de la justicia privada de Hevia, el contenido de estas normas es muy difícil de acomodar. Si mi argumento fuese correcto, Hevia podría explicar únicamente la facultad de las partes de auto-obligarse, entendiendo por esto la facultad de entrar en un régimen de intercambio en el cual muchas de las pautas son dictadas por la justicia distributiva y no por la justicia correctiva. Una vez que las partes adhieren al sistema de intercambio, el incumplimiento y los remedios sí pueden ser explicados por la justicia correctiva. Pero ello limita significativamente el carácter privado de los contratos que Hevia se propone enfatizar desde la primera página de su libro.

${ }^{39}$ Weinrib, E., The Idea of Private Law, Cambridge-Mass, Harvard University Press, 1995. Para los argumentos a favor de los estándares variables véase Keren-Paz, T., Torts, Egalitarianism and Distributive Justice. Hampshire, Ashgate, 2007. 


\section{El vigoroso consensualismo kantiano y el (no tan) estricto efecto relativo de los contratos}

Para finalizar este comentario a la obra de Hevia, quisiera llamar la atención sobre dos cuestiones no relacionadas directamente con el aspecto distributivo del derecho contractual, pero que pueden terminar teniendo alguna incidencia sobre esto. La primera tiene que ver con que el carácter dominante del consensualismo en la teoría kantiana de los contratos hace difícil explicar la exigencia de formas para la validez de algunos contratos ${ }^{40}$. Asimismo, estrechamente vinculado con esto, los llamados contratos reales son el contraejemplo típico de la insuficiencia del consentimiento para generar obligaciones jurídicas. Todas estas normas socavan la función que la teoría kantiana asigna al consentimiento. La segunda cuestión que deseo señalar es que el efecto relativo de los contratos que Hevia toma como un dogma inquebrantable admite al menos dos excepciones notables y normativamente muy razonables: la acción subrogatoria y la acción directa.

En la teoría de Hevia el consentimiento es condición necesaria y suficiente para la formación de un contrato válido. Tal como concibe Hevia los contratos, ellos son el instrumento necesario con el cual los individuos pueden disponer de sus bienes según convenga a su plan de vida. Digo "necesario" porque para Hevia no tendría sentido que las personas tuviesen recursos sin la facultad de disponer de ellos, lo que incluye la facultad de transferirlos o ponerlos al uso de un plan común con otros individuos ${ }^{41}$. Cuando las personas persiguen su plan de

${ }^{40}$ Sobre el principio de consensualismo y la exigencia de formas, véase Rezzónico, J. C., Principios fundamentales de los contractos, Buenos Aires, Astrea, 1999.

${ }^{41}$ Hevia, M., "Razonabilidad y responsabilidad: Rawls, Kant y la teoría del derecho contractual", op. cit. No criticaré esta idea en el texto principal, pero me parece muy controvertido afirmar que el sentido de contar con recursos dependa de poder intercambiarlos. Es perfectamente concebible un sistema en el cual los individuos tengan derechos de propiedad limitados al uso, pero carezcan de la facultad de disponer libremente de sus bienes. Podrían tener facultades de excluir a otros y de destinar el recurso como mejor les venga en gana, sin por ello contar con la alternativa de dejarlo al 
vida celebrando contratos con otros, la idea de igual libertad requiere que se cumplan los términos del acuerdo. En la teoría kantiana, la voluntad común de las partes debería ser suficiente para vincularlas jurídicamente. No obstante, los contratos formales ad solemnitatem, como la donación de inmuebles en el derecho argentino, son nulos si no se celebran respetando la forma establecida por el legislador (art. 1810 CC), con independencia de cuán clara haya sido la voluntad común de que ese acto produzca efectos vinculantes. También podemos relacionar esta cuestión de la forma con el problema de los contratos reales, que solo se perfeccionan con la entrega de la cosa. El contrato de mutuo, por ejemplo, solo produce efectos desde la traditio. Axileas y Xenofonte pueden haber pactado que el día 8 de enero de 2014 Axileas prestaría a Xenofonte una suma de dinero, por ejemplo, que Xenofonte la restituiría de tal y cual manera, etc., pero el contrato no se perfecciona si el día 8 de enero Axileas no entrega el dinero a Xenofonte. La respuesta jurídica para estos casos es bien diferente de la consensualista, pues si la promesa fue gratuita Xenofonte carece de acción para exigir el cumplimiento, mientras que si fue onerosa solo tendría derecho a demandar en el plazo de 3 meses una indemnización por los daños sufridos (art. 2244 CC), pero no por la expectativa, que es el remedio natural en la teoría kantiana, como pone de manifiesto Hevia en reiteradas ocasiones ${ }^{42}$. Estos casos muestran que

uso ajeno a cambio de algo o gratuitamente. No veo por qué un derecho como este carecería de sentido. El derecho contractual no es un instrumento imprescindible en este esquema. Después de todo, en cualquier sistema hay proyectos de vida prohibidos. Así, los recursos son útiles únicamente para los proyectos permitidos, lo que no incluye (en este sistema hipotético) emprender planes conjuntos con los bienes provistos por el Estado. No hay nada incoherente en esto, por lo tanto, Hevia no puede afirmar que el derecho contractual es una necesidad conceptual para la coherencia de un sistema que reconoce a los individuos ciertos recursos. Lo único que puede afirmar es que un sistema como este sería normativamente implausible, y esto tampoco me parece incontrovertible.

${ }^{42}$ Hevia, M., Reasonableness and Responsibility: A Theory of Contract Law. Dordrecht, Springer, 2013; Hevia, M., "Razonabilidad y responsabilidad: Rawls, Kant y la teoría del derecho contractual", op. cit. 
el consensualismo no es un principio inquebrantable, sino que tiene muchas excepciones que han de ser explicadas con principios externos a la autonomía de la voluntad. Cuando Axileas y Xenofonte acuerdan el mutuo a ejecutarse el 8 de enero de 2014, ejercen su libertad autónomamente y deben asumir su responsabilidad por ello ${ }^{43}$. Si la teoría kantiana fuese correcta, las categorías de los contratos reales o los contratos formales no existirían, dado que la única "formalidad" necesaria y suficiente debería ser la expresión del consentimiento.

Respecto del efecto relativo de los contratos, a mi parecer Hevia pone demasiado énfasis en que "solo las partes del contrato pueden invocar los derechos y deberes que surgen de él" 44 . Las obligaciones contractuales pertenecen a la clase de las obligaciones en general, y el régimen común de las obligaciones suele incluir normas sobre subrogación para lidiar con el problema de los deudores que al mismo tiempo son acreedores inactivos (aquellos que no ejercen los derechos que tienen contra otros simplemente para no responder frente a sus propios acreedores). Así, la doctrina entiende que los acreedores que ejercen la llamada acción oblicua tienen a su alcance todos los derechos del deudor, como

solicitar medidas cautelares; interrumpir la prescripción; pedir la anotación y reinscripción de prendas e hipotecas; oponer la prescripción; pedir el cumplimiento, la resolución, la rescisión o la revocación de contratos celebrados por el deudor, y reclamar daños que hayan derivado de su incumplimiento; etcétera ${ }^{45}$.

En estos casos, el demandado solo puede oponer las defensas que hubiesen sido válidas contra su acreedor (es decir, el deudor subrogado).

A la vez, el derecho también suele admitir la acción directa mediante la cual el acreedor demanda a un tercero que debe una prestación a su deudor. La explicación de esta figura puede resultar confundente, por

${ }^{43} \mathrm{Al}$ menos, esto es lo que debería afirmar Hevia (Hevia, M., "Razonabilidad y responsabilidad: Rawls, Kant y la teoría del derecho contractual", op. cit.).

${ }^{44}$ Hevia, M., Reasonableness and Responsibility: A Theory of Contract Law. Dordrecht, Springer, 2013.

${ }^{45}$ Alterini, A. A., Contratos. Buenos Aires, Abeledo-Perrot, 1998. 
lo que conviene ilustrar con un ejemplo. Imaginemos que Xenofonte alquila un bien inmueble a Telémaco, y que este a su vez lo sub-alquila a Axileas. En estas circunstancias, si Telémaco debe alquileres a Xenofonte, Xenofonte tiene la facultad jurídica de exigir el pago del alquiler directamente a Axileas, sin tener que demandar a Telémaco. La cuestión es que entre Xenofonte y Axileas no existe vinculación contractual alguna, pero Xenofonte cuenta con la potestad jurídica de invocar el contrato que Axileas tiene con Telémaco para cobrar del primero lo que el segundo le debe ${ }^{46}$.

Tanto la subrogación, pero especialmente la acción directa, quiebran la lógica del efecto relativo de los contratos de modo importante. Los derechos y deberes que surgen de los contratos, como cualquier otro derecho o deber, pueden ser invocados en las condiciones descriptas por terceros que no forman parte del negocio jurídico. La estructura bilateral del derecho privado y el carácter puramente voluntario de las obligaciones contractuales parecen ser un dogma orientado a ocultar que el derecho privado también puede ser utilizado para perseguir políticas sociales. En el caso de la acción directa, la norma parece bastante razonable y apunta a minimizar los costes de la satisfacción del crédito, por una parte, y a mejorar las perspectivas de cobro del acreedor, por la otra. No veo en el derecho privado nada sagrado, nada que pueda ser desnaturalizado, ni ninguna tragedia en el uso de este conjunto de normas para la promoción de directrices de política pública. La exaltación de estos dos mitos relacionados (la autonomía de la voluntad y el efecto relativo de los contratos) podría no hacer más que alejarnos de la verdadera "naturaleza" del derecho privado que, como todo el derecho, es un instrumento que puede ser utilizado para el fin social que consideremos conveniente.

${ }^{46}$ Véase la explicación de Alterini, A. A., Contratos. Buenos Aires, AbeledoPerrot, 1998. 


\section{Recapitulación y palabras finales}

En el desarrollo precedente he seguido el siguiente orden. En primer lugar, he sostenido que Hevia no logra mostrar que su teoría se distinga de modo relevante de las concepciones libertarias en lo que hace al derecho contractual. Por supuesto, mantiene un desacuerdo profundo con los libertarios en el nivel de la teoría de la justicia, pero no termino de ver con claridad qué impacto tendría ello para la manera en que Hevia concibe las interacciones contractuales. Al parecer, tanto Hevia como los libertarios asumen que los contratos son el modo legítimo que los individuos tienen a su disposición para transferirse mutuamente derechos y deberes, según lo requiera el plan de vida escogido por cada uno. En segundo término, he afirmado que las razones que Hevia tiene para rechazar las visiones distributivistas del derecho contractual no son concluyentes. He elaborado un argumento para mostrar que la teoría de Kronman es inmune a las dificultades explicativas apuntadas por Hevia. El paretianismo de Kronman, que debe distinguirse del criterio utilitario de Pareto, puede dar perfectamente cuenta del rol del consentimiento en las interacciones privadas y también del efecto relativo de los contratos. Alternativamente, he sugerido un modo de interpretar el derecho contractual de acuerdo con el cual existe un fuerte componente público en las razones para ejecutar forzosamente los términos de los acuerdos privados. En esta lectura, el principio de división de la responsabilidad, que tanto Hevia como Ripstein invocan para trazar los límites de la justicia distributiva y la justicia correctiva, se fundamenta en consideraciones distributivas. La justicia correctiva, como principio de justicia parece diluirse en las teorías dinámicas como una parte necesaria de la justicia procedimental pura. Aunque estos argumentos no fuesen del todo convincentes, los partidarios de la justicia privada todavía deberían explicar cómo es posible que la mayoría de los derechos y deberes que surgen para las partes una vez que celebran un contrato no emanan de la autonomía de la voluntad. $\mathrm{Su}$ acuerdo solo regula un aspecto de la relación, pero en realidad el consentimiento funciona más como un mecanismo de entrada al mundo de las interacciones entre particulares, y este es un mundo 
fuertemente regulado, tanto en el régimen del Código Civil como en el estatuto de defensa de los consumidores y usuarios.

Por último, he llamado la atención sobre el hecho de que la caracterización de Hevia del derecho contractual como bilateral, estrictamente privado, fundado en la justicia correctiva, compatible con la justicia distributiva pero sin incorporar esta forma de justicia en la justificación de las obligaciones que surgen del contrato es descriptivamente inadecuada. Acabo de mostrar que existen excepciones importantes a la autonomía de la voluntad y al principio de consensualismo, y también que el supuesto efecto relativo de los contratos no es tan estricto como a veces se sostiene. Es indudablemente cierto que la responsabilidad que surge de los contratos es particular y, con pocas excepciones, limitada a quienes los celebran, pero tal vez por esta razón la levedad de la justicia correctiva en este ámbito del derecho sea insoportable para los teóricos de orientación kantiana. Del mismo modo en que Hevia se esfuerza por compatibilizar la libertad con la justicia distributiva, me he propuesto compatibilizar la justicia distributiva con la responsabilidad personal. Si mi argumento es plausible, habrá que entender que el derecho privado es privado porque deja en manos de los particulares el establecimiento de responsabilidades personales en mayor medida que el llamado derecho público, sin que ello vaya en desmedro de reconocer que el problema que se aborda desde el derecho privado tiene una importante e innegable dimensión pública.

\section{Bibliografía}

Alterini, A. A., Contratos. Buenos Aires, Abeledo-Perrot, 1998.

Alterini, A. A. y López Cabana, R., La autonomía de la voluntad en el contrato moderno. Buenos Aires, Abeledo-Perrot, 1989.

Aristóteles, Ética Nicomaquea, Madrid, Editorial Gredos, 1985.

Barnett, R., A Consent Theory of Contract, Columbia Law Review, 1986, citado por la traducción de Haymes, G. I. y Papayannis, D. M., La teoría consensual del contrato, Lecciones y Ensayos, 2006.

Barnett, R., Some Problems with Contract as Promise, Cornell Law Review, 1992. 
Bobbio, N., El positivismo jurídico, Madrid, Debate, 1998.

Coleman, J. L., "The Structure of Tort Law", en Yale Law Journal, 1988. Fried, C., Contract as Promise. A Theory of Contractual Obligation, Cambridge-Mass, Harvard University Press, 1981.

Gardner, J., "Justicia correctiva" (corr.), en Papayannis, D. M. (de.), Derecho de daños, principios morales y justicia social. Madrid-BarcelonaBuenos Aires, Marcial Pons, 2013.

Hevia, M., Reasonableness and Responsibility: A Theory of Contract Law. Dordrecht, Springer, 2013.

Hevia, M., "Razonabilidad y responsabilidad: Rawls, Kant y la teoría del derecho contractual", Discusiones, XV, 2014, págs. 15-47.

Keren-Paz, T., Torts, Egalitarianism and Distributive Justice. Hampshire, Ashgate, 2007.

Kronman, A., Contract Law and Distributive Justice, Yale Law Journal, 1980.

Murphy, L. B., Institutions and the Demands of Justice, Philosophy and Public Affairs, 1999.

Nozick, R., Anarchy, State, and Utopia. Oxford, Blackwell Publishers, 1974.

Rawls, J., "Social Unity and Primary Goods", en Sen, A. y Williams,

B. (eds): Utilitarianism and Beyond. Cambridge, Cambridge University Press, 1982.

Rawls, J., A Theory of Justice, (Revised Edition) Cambridge, Mass., Harvard University Press, 1999.

Rezzónico, J. C., Contratos con cláusulas predispuestas, Buenos Aires, Astrea, 1987.

Rezzónico, J. C., Principios fundamentales de los contractos, Buenos Aires, Astrea, 1999.

Ripstein, A., The Division of Responsibility, Fordham Law Review, 2004.

Weinrib, E., "Understanding Tort Law", en Valparaiso University Law Review, 1989.

Weinrib, E., The Idea of Private Law, Cambridge-Mass, Harvard University Press, 1995.

Zago, J. A., El consentimiento en los contratos y la teoría de la lesión, Buenos Aires, Editorial Universidad, 1981. 